How to cite: Vasile, D.M., Popa, M.C., Toma, F., Diaconu, D.C. (2021) Flash Flood Assessment Using GIS and the Frequency Ratio Bivariate Statistical Model - Case Study, Codlea, Romania. 2021 "Air and Water Components of the Environment" Conference Proceedings, Cluj-Napoca, Romania, p. 61-74, DOI: 10.24193/AWC2021_06.

\title{
FLASH FLOOD ASSESSMENT USING GIS AND THE FREQUENCY RATIO BIVARIATE STATISTICAL MODEL - CASE STUDY, CODLEA, ROMANIA
}

\author{
Diana Marinela VASILE ${ }^{1}$, Mihnea Cristian POPA ${ }^{1}$, Florentina TOMA ${ }^{1}$, Daniel \\ Constantin DIACONU ${ }^{2 *}$
}

DOI: $10.24193 / A W C 2021 \_06$

\begin{abstract}
Floods are one of the biggest natural disasters, causing significant economic and human losses. Regardless of the degree of development of urban or rural systems, floods account for about a third of all-natural disasters globally. Identifying areas vulnerable to floods is essential for better management and mitigation of their effects. The research aims to identify areas vulnerable to floods in the city of Codlea, Brașov County. Annually, the city records significant floods, one of the determining factors being its location, near the southern slope of the Perșani Mountains. The research proposes the Flash Flood Potential Index (FFPI) computation by combining GIS techniques with the Frequency Ration bivariate statistical model. The correlation of various flash-flood conditioning variables allowed us to compute the FFPI. The methodological approach could represent an essential tool for local authorities for better flood risk management.

Keywords: Flood, vulnerability, Flash Flood Potential Index, GIS, Codlea.
\end{abstract}

\section{INTRODUCTION}

Over the years, most natural disasters have been caused by floods and floods. Floods represent a hazardous phenomenon as they cannot be predicted in due time. Thus, the intervention time becomes short. Floods cause significant human and economic losses worldwide, increasing significantly in the last three decades (Costache 2019a). Between 1996 and 2015, there were 150,061 victims of floods (Gashaw and Legesse 2011). The complex interaction between several meteorological, hydrological, geomorphological, geological, and anthropogenic factors (Wu and Sidle 1995) produce floods with drastic environmental and socioeconomic consequences (Greg et al. 2003).

Floods are rapid increases in flow that occur in a short period of time in a river basin (Clar et al. 2013) generated by high-intensity precipitations, by the sudden melting of snow, or by the sudden release of accumulated water (dam failure).

\footnotetext{
${ }^{1}$ Simion Mehedinți "Nature and Sustainable Development" Doctoral School, University of Bucharest, Nicolae Bălcescu, No.1, Romania, E-mail: diana.vasile@drd.unibuc.ro, florentina.ghersin@drd.unibuc.ro,popamihneacristian@gmail.com

${ }^{2}$ Centre for Integrated Analysis and Territorial Management, University of Bucharest, Blv. Regina Elisabeta 4, București 030167, Romania, daniel.diaconu@unibuc.ro *correspondence author
} 
The negative impact of floods can be reduced by adopting measures and actions specific to areas with a high frequency of this phenomenon. These are also the Intergovernmental Panel's recommendations on Climate Change (IPCC)(Barredo et al. 2007; Paprotny et al. 2017). The European Floods Directive 2007/60 and Directive 2008/94 / EC of the European Parliament and the Council, published in the Official Journal of the European Union, deal with the analysis of European rivers accordingly, while flood and hazard mapping are done using GIS, hydraulic modelling or statistics (Kruzdlo and Joseph Ceru n.d.).

A flood's characteristics are determined by the intensity of precipitation, land use, soil type, vegetation type, topographic characteristics, and initial water level (Sima and Șerban 2015). Depending on the geographical characteristics (soil texture, slope, land use, rock permeability, etc.), the hydrological response is different. Meteorological factors remain an essential factor in generating floods. If high-risk areas are identified, and early warnings are issued, the number of human and economic losses can be reduced. (Barredo 2007).

In the United States, within the project "The Flood Project in the Western Region", the FFPI index was developed and tested in several regions. Over the years, the index has undergone multiple changes. This index can show the probability of an area to be flooded. Barredo (Popa et al. 2019; Tîrnovan et al. 1975; Zaharia et al. 2012), used this method, to map the major flood disasters in Europe between 1950 and 2005.

In Romania, several researchers computed the index to test its accuracy (Diaconu et al. 2019; Drăghici et al. 2017; Hofmann and Schüttrumpf 2019; Pintilii et al. 2017; Zeleňáková et al. 2015)

This study proposes using Flash Flood Potential Index (FFPI) and the frequency ratio (FR) bivariate statistical model. The paper aims to provide a methodological approach for testing the FFPI and to validate the results in urban areas. The index was also tested on river catchments with no hydrotechnical constructions. A calibrated and validated study for urban areas can help to facilitate the management of water resources and reduce the negative effects on urban settlements.

\section{STUDY AREA}

The town of Codlea is located at the foot of Măgura Codlei mountain (1294 m altitude), which is part of the Perșani Mountains, Curvature Carpathians. However, the city is situated on the flat plain with a piedmontese character of the Vulcăniţa river (Fig. 1). The total area of Codlea is 12,520 hectares, the built-up area representing 1,217 hectares. Approximately 50\% of the built-up area is located in a plain area with a flat appearance; $25 \%$ of the built-up area is found on the deluvial slopes that have an accentuated slope of $15-30 \%$. The rest of the urban surface is located in the northwest at the foot of Măgura Codlea Mountain.

From a geological point of view, there is a complex substrate specific to the area consisting of sedimentary deposits of the Cretaceous flysch, Quaternary deposits, volcanic formations, but also rock reserves, such construction materials (clays, 
sands, limestones, sandstones, gravel, etc.). The city of Codlea presents a climate strongly modified by the local physical-geographical conditions, meeting a westerncontinental continental climate with oceanic influences and an excessive-continental climate from the east, is dominated by the atmospheric circulation from the northwest.

The average multiannual temperature of the locality is $+7.8^{\circ} \mathrm{C}$, and the winds are influenced by the local topography. The average annual number of days with precipitation is 138 days, and in summer, frequent torrential rains are exceeding the value of $20 \mathrm{l} / \mathrm{m}^{2}$.

The territorial administrative unit is crossed by 7 rivers, Bârsa, Vulcăniţa, Homorod, Geamăna, Popîlnica, Crepeş and Turcu. Codlea has 3 lakes, Codlea Lake I - 2.7 ha, Codlea Lake II - 4.5 ha, Hamaradia Lake - Dumbrăviţa - 121 ha.

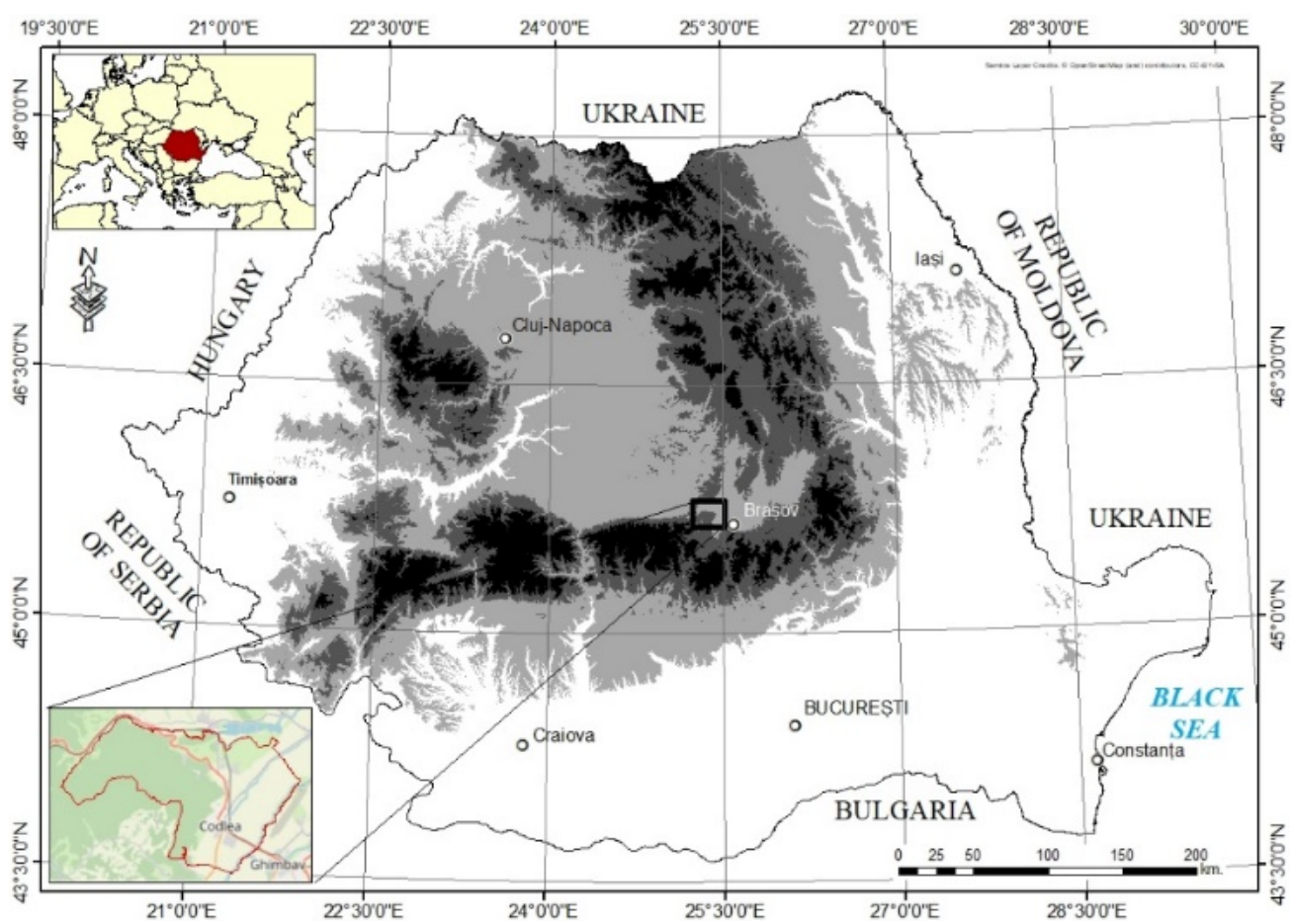

Fig. 1. Location of the study area.

\section{METHODOLOGY AND DATA}

In order to compute the proposed models, a selection of flood conditioning variables was made, which are based on hydrological and geospatial information. The main 3 stages used in the methodological development are: collection and processing of geospatial data, computation of the Flash Flood Potential Index (FFPI), and the validation of results. This study uses 6 flash flood conditioning variables to 
compute the FFPI, which are: slope, plane curvature, profile curvature, slope appearance, land use and topographic humidity index (TWI).

Most of the factors were made using the Digital Terrain Model (DEM), which was extracted from the EU-DEM dataset, which is available for download at the European Environment Agency, with a spatial resolution of $30 \mathrm{~m}$. Slope, appearance slope, plane curvature, profile curvature and topographic humidity index were generated from the Digital Elevation Model. The land use was enhanced with the help of the CORINE Land Cover 2018 data set. With the help of the ArcGIS 10.8 program, all transformations and operations were performed, and the data captured in vector format were converted to raster format. Including for this data transformed from vector to raster, a resample was made at a resolution of $30 \mathrm{~m}$, in order to have a uniformity between the raster data.

The classification of the slope was made in five classes that show us the degree of slope of the terrain (Table 1 and Figure 2.a.). The appearance of the slope is an important variable because the orientation of the slope has a great influence on soil moisture (Figure 3.a.). Thus, the appearance of the slope was classified into five classes that serve the orientation of the slopes.

The topographic humidity index is a morphometric factor that indicates soil moisture and shows the tendency of water distribution on the soil (Figure 2.b.). The variable was classified into five classes between 3.22 and 18.21.

The curvature of the Plan is the variable that shows the areas with a flow of divergence or convergence, it was classified into five classes between $\div 3.26$ and 3.13 (Figure 2.c.). The curvature of the profile indicates the direction of the maximum slope of the analysis area (Figure 2.d.). This variable was classified into five classes, ranging from $\div 3.45$ to 3.44 . The negative values represent the fact that the surface is convex upwards, the positive ones are concave upwards, and those close to 0 represent the linear surface. Land use was classified into five land use classes, which were grouped according to their characteristics (Figure 3.b.).

To use the FFPI in detecting areas prone to floods, we used the method called the frequency ratio (FR). This model is a bivariate statistical method that is used in the study of large-scale mapping of landslides and floods (Nohani et al. 2019; Samanta et al. 2018). In the present study we propose to use the FR model to detect and map areas that are prone to floods and floods in Codlea. The frequency ratio model is probabilistic, easy to apply and simple to understand, which determines the ratio of occurrence or non-occurrence of a phenomenon such as floods and floods present in the study area (Bonham-Carter 2014).

Flood and flood conditioning variables together with areas affected by torrentiality or the location of historical floods are the basis of the FR method. This frequency ratio is determined by analyzing the relationship between flood or flood locations and the factors used and is presented together with the prediction ratio (RP) in Table 1. The prediction ratio may have high values indicating that the factor is quite influential. much generating floods, floods or surface leaks. In this case PR was determined using the spatialization of each variable in the training set and calculated using equation (eq.1) (Althuwaynee et al. 2014): 


$$
P R=\frac{\left(S A_{\max }-S A_{\min }\right)}{\left(S A_{\max }-S A_{\min }\right) \min }
$$

where $P R$ represents the prediction ratio for each variable and SA represents the association between the floodable or torrential locations and the minimum and maximum spatialization between the variables.

The weights were calculated in Microsoft Excel for each index and were compared and validated using a pair comparison matrix. Flood or flood conditioning variables in raster form were reclassified using relative frequency (RF) values calculated from the following equation (eq.2):

$$
R F=\frac{R_{+}}{R_{\text {tot }}}
$$

where $R F$ represents the relative frequency, $R_{+}$represents the positive ratio, and $R_{t o t}$ represents the sum of each positive ratio of a certain factor.

In the ArcGIS we inserted 165 flood points on the entire studied area and we established the class area for each factor. The number of points and the area of the classes were calculated as percentages, later with their help we found the positive ratio (Ratio $(+)$ ), dividing the percentages of the number of points by the percentages of each area of the class for each class. positive for each variable.

The relative frequency is calculated for each variable separately, dividing the positive ratio by classes to the total sum of the positive ratios, at the end calculating their total sum which must be equal to 1 (eq.2.). The relative frequency was used to reclassify the maps in the ArcGIS program, using the Reclassify function. The next step is to find out the prediction ratio for each variable using the equation (eq.1). Prediction ratio values were used in the ArcGis program in the Raster Calculator function to determine the final FFPI map using the following function (eq.3):

$$
F F P I=(3,40 \times S l)+(1,23 \times S a)+(1,83 \times T W I)+(1,71 \times P c)+(1,04 \times P l c)+(1 \times L u)
$$

where $S l$ is the slope, $S a$ is the slope aspect, $T W I$ is the topographic humidity index, $P c$ is the profile curvature, $P l c$ is the plane curvature, $L u$ is the land use, and the numbers represent the prediction ratio values for each variable. (Costache et al. 2019; Zaharia et al. 2017).

\section{RESULTS}

Considering the data obtained (table 1, Fig. 2-3), we can observe the areas prone to flooding.

Regarding the slope map, the largest area of the studied area has a slope between $0-3.48^{\circ}$, representing $47.79 \%$ of the total area. In contrast, the areas where the highest torrentiality is identified are found. On the highest slopes, between 24.62 - 
$46.82^{\circ}$, representing $3.37 \%$. The city of Codlea is located in a meeting area of the five classes analyzed. Being at the base of the Măgura Codlei massif, which has a high slope (between $24.62-46.82^{\circ}$ ), a significant part of the amount of precipitation drains quickly on the slope and subsequently stagnates in the area with a reduced slope.

Table 1. Frequency and prediction ratio and the distribution of the flood locations and classes of each flash-flood conditioning variable.

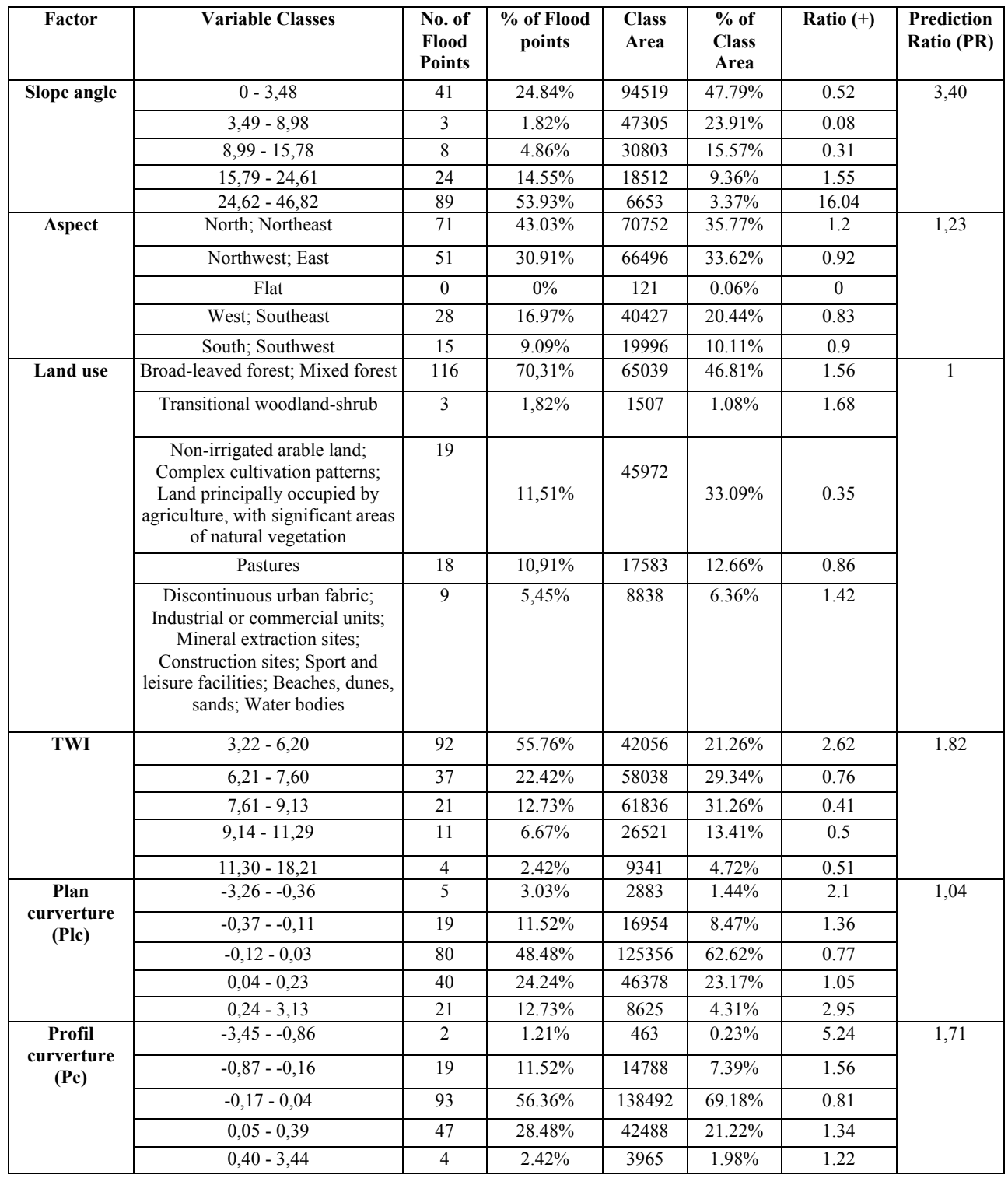


The aspect shows the orientation of the slopes, which is divided as follows: the flat areas representing the smallest percentage of the surface, more precisely $0.06 \%$, the group formed by the North orientations; Northeast, represents the largest coverage of the total area, more precisely $35.77 \%$, followed closely by the group formed with Northwest; East of 33.62\%, then follows the West category; Southeast with a percentage of $20.44 \%$ of the total, and the last class is represented by the South group; Southwest occupying the area of $10.11 \%$. These guidelines help us realize the soil moisture, the release of water from the snow layer, and the areas that dry faster depending on the sunshine's degree.

The topographic wetness index (TWI) has the highest coverage in the range of $7.61-9.13$, representing $31.26 \%$ of the studied area, and the lowest coverage is in the range $11.30-18.21$ by $4.72 \%$. This last interval is also the area with the lowest humidity degree, being located mainly on slopes or on lands that have a higher slope. Thus, the slopes generate water drainage to areas with a lower slope and help dry the slopes much faster than the area with small slopes that retain a more extended period of time and a more significant amount of water moistening the soil. In Codlea locality, high values of the topographic humidity index can be observed because there are large slopes and valleys between them that collect a more considerable amount of water and transport it to the locality, thus further flooding the area west of the city.

The plan's curvature has in classification five classes where the highest values are found on an area of $62.62 \%$ of the total area, belonging to the class of $\div 0.12$ and 0.03 . The negative values indicate the convergence of the area, the positive ones its divergence, and those close to 0 suggest that we have a linear surface. Thus, for our study area, the highest values are found in the ranges $\div 0.12-0.03$ and $0.04-0.23$, on an area of $62.62 \%$, respectively $23.17 \%$. The range $\div 3.26-\div 0.36$ occupies the entire surface's smallest coverage, more precisely $1.44 \%$. These data can also be seen in Fig. 2.c.

The most significant convergence areas are easily noticed, occupying a small area and being located mainly in the Persian valleys. The studied area is primarily occupied by values that approach the value 0 ; they indicate a linear surface.

The profile curvature is classified on our area between the values $\div 3.45$ $\div 0.86$ and $0.40-\div 3.44$. The negative values represent that the surface is convex, the positive ones are concave, and the ones close to 0 represent the linear surface. The curvature of the profile has the largest surface, of $69.18 \%$, which represents the class with values between $\div 0.17$ and 0.04 , followed by the interval $0.05-0.39$, which occupies the surface of $21.22 \%$, and the area with the lowest percentage of coverage by $0.23 \%$, is represented by the range $\div 3.45$ $-\div 0.86$. Thus, as in the case of the curvature of the plane, the largest areas are those close to 0 , and the smallest are the negative values, only in the case of profile curvature, the smallest values are found at the highest altitudes of the area, they being convex, they do not retain water, and the most extensive are those with a narrow slope, so they are concave and retain water. 
Land use is the type of use of the area studied by classes grouped according to shared characteristics. The largest area of the studied area is occupied by the class that meets the following types of land use: Broad-leaved forest; Mixed forest. It occupies $46.81 \%$ of the total area and is made up of areas occupied by types of trees.
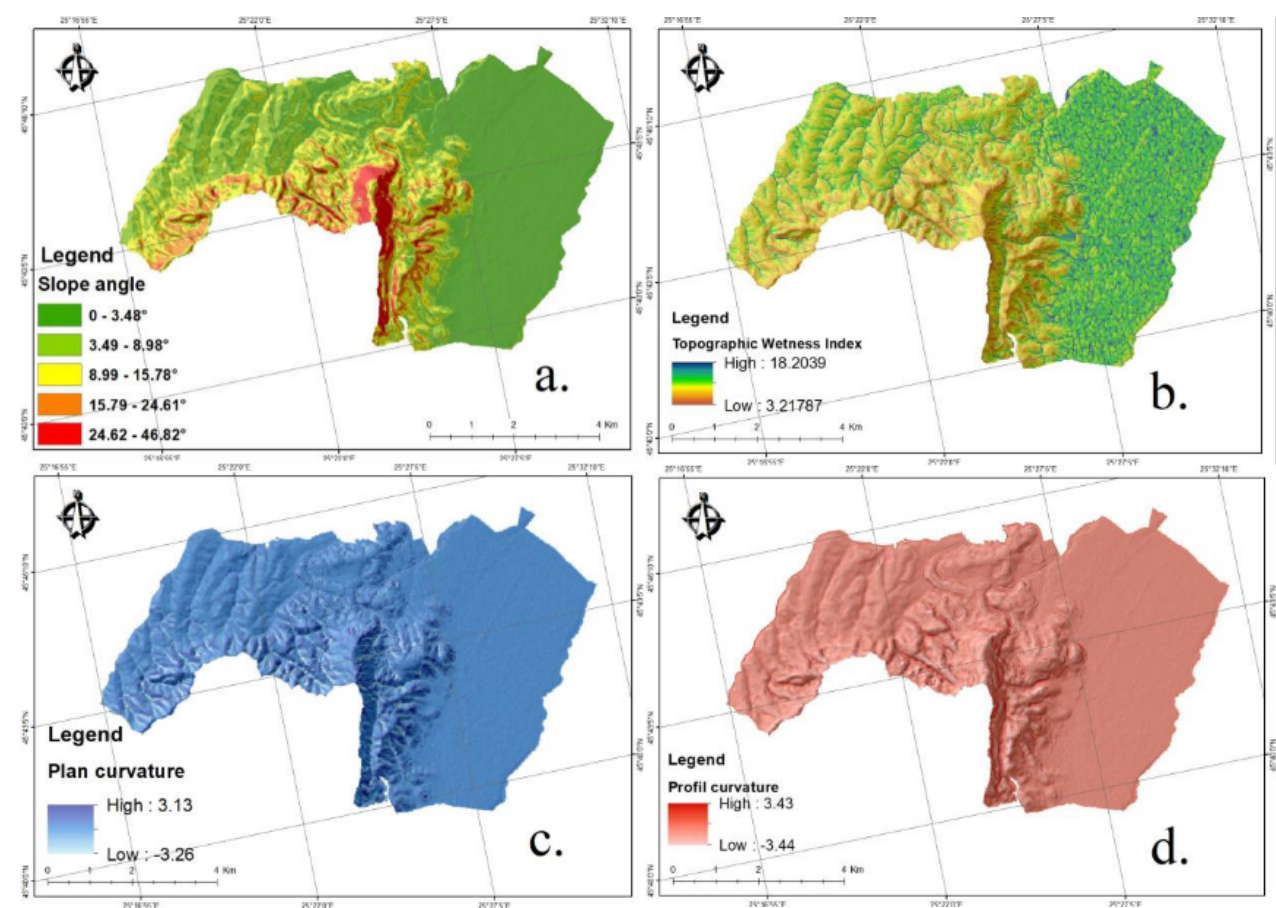

Fig. 2. Slope angle (a.), Topographic Wetness Index (TWI) (b.), Plan Curvature(c.), Profil Curvature (d.)

As land occupation, the next category is represented by the class of agricultural areas, which consists of the following classes: Non-irrigated arable land; Complex cultivation patterns; Land mainly occupied by agriculture, with significant areas of natural vegetation and occupies an area of $33.09 \%$. The next class occupies the area of $12.66 \%$ and is occupied by Pastures.

The urban space occupies $6.36 \%$ and consists of Discontinuous urban fabric; Industrial or commercial units; Mineral extraction sites; Construction sites; Sport and leisure facilities; Beaches, dunes, sands; Waterbodies. And the area with the smallest area is occupied by Transitional woodland-shrub, with a percentage of $1.08 \%$.

Using the geoprocessing and spatial analysis tools available ArcGIS, and based on the presented indicators, the FFPI map was generated (Fig. 4).

The result classified into five classes, very low, low, medium, high and very high. The lowest values indicate the areas less prone to flooding, being flat surfaces, while the highest values indicate the areas susceptible to flooding. 

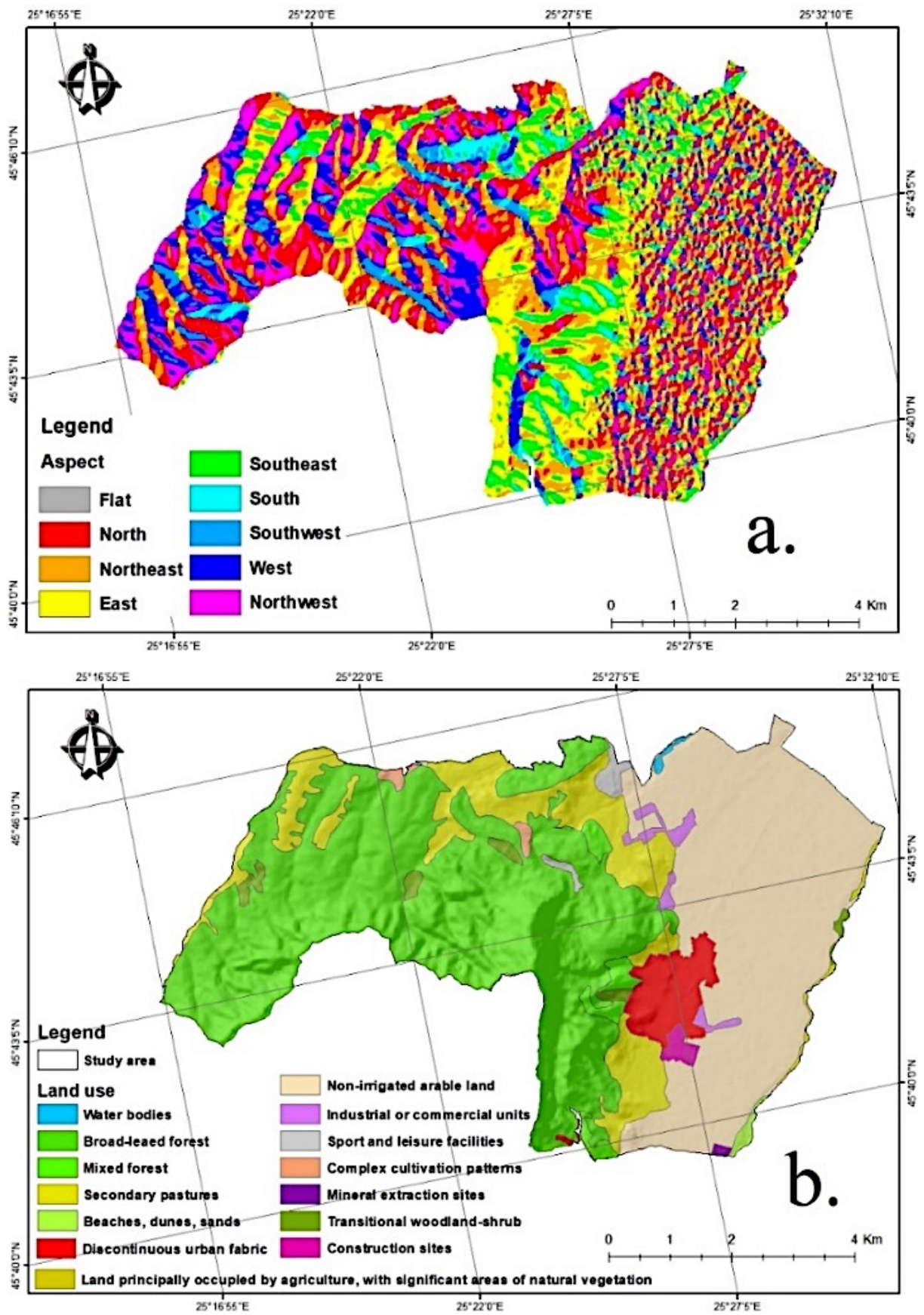

Fig. 3. (a.) Aspect, (b.) Land Use 
The very low class overlaps $40.77 \%$ of the study area, being the largest of all five classes. The low risk class occupies $29.87 \%$ of the study area. The high-risk class occupies $18.02 \%$ of the study area. The medium-risk class occupies $7.97 \%$. The very high-risk class occupies $3.37 \%$.

In our study area, the highest values can be observed at the highest altitudes on the slopes. Thus, their high slope favors the flow of water to the small slopes, respectively, to the City of Codlea. The high degree of waterproofing of the land (asphalt roads, concrete ditches) generates a high-water movement speed and a low infiltration underground.

The Vulcănița River crosses the mountainous area, later reaching to cross the city through its Eastern part, having an orientation to the North-East. At the time of a flood, the river's flow increases significantly, being quickly fed from the upper part of the river basin.

The slopes' precipitation flows towards the city, approximately simultaneously with the maximum flows on the river. The effect is flooding large areas throughout the city.

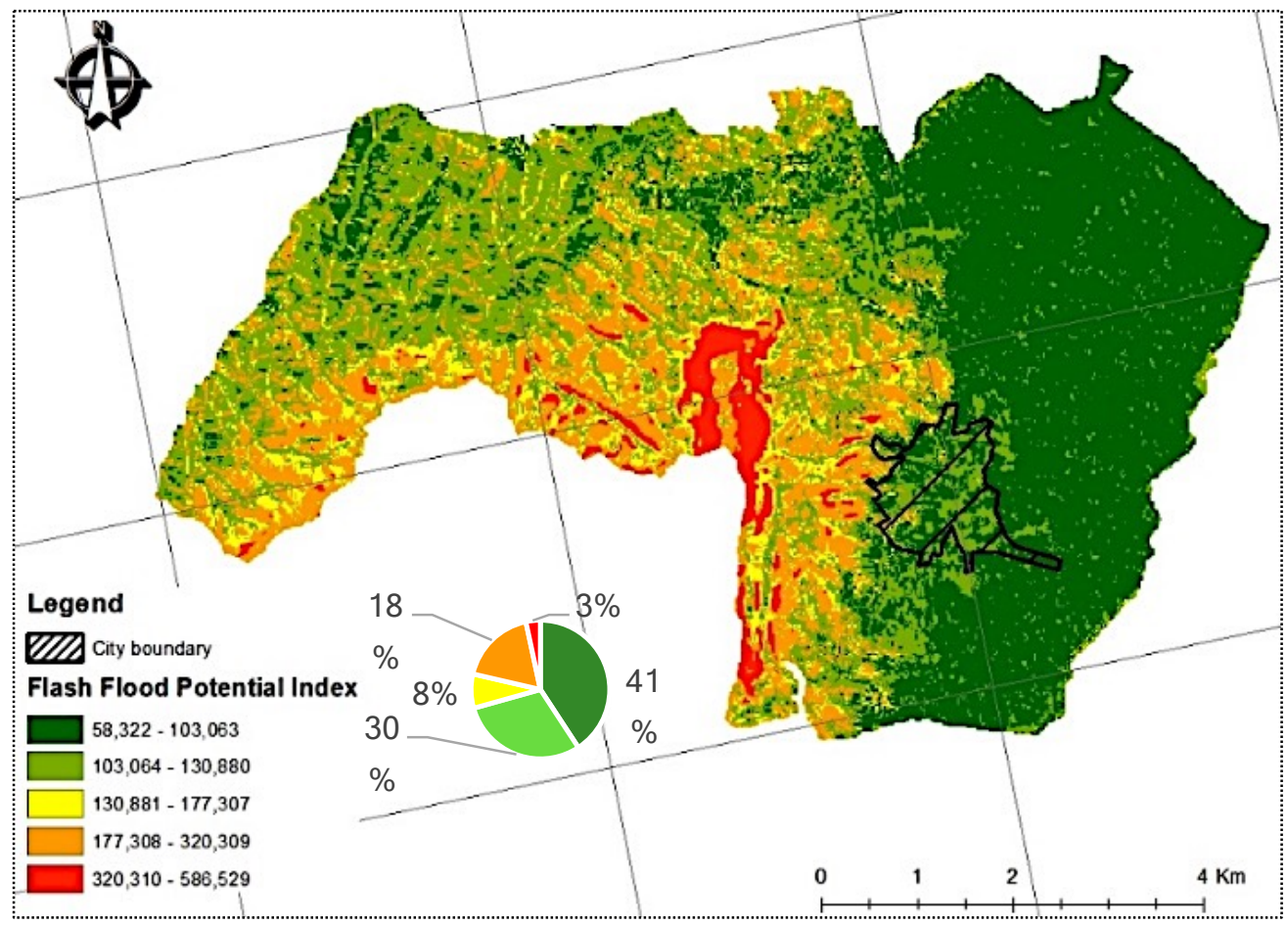

Fig. 4. Flash Flood Potential Index

\section{DISCUSSION}

In the present study, with the help of the FFPI method, we provided a way to determine floods in hydrologically unmonitored areas, thus covering a dysfunction 
mentioned in numerous studies that aimed to model the risk of flooding (Costache 2019b; Costache et al. 2020; Minea 2013; Popa et al. 2020; Zeng et al. 2016).

The developed methodology allows the understanding of the complexity of physical-geographical factors that compete for floods' specific manifestation. Most of the studies carried out so far, which are based on the FFPI method, analyze a river basin (Feyen et al. 2012), so that through the proposed methodology we want to show that assessments can be made on smaller areas, thus solving a major methodological problem, the identification of floodable regions at the level of the surfaces of some localities.

This methodology's development shows the relevance of open-source data in flood analysis, thus solving an essential obstacle for researchers (Veijalainen 2012). The obtained results show a necessity and a priority for developing the methodologies that analyze the vulnerability to floods and territorial planning. Current methods of anticipating the effects of floods are difficult to apply to small geographical areas.

The research shows methodologies that assess areas vulnerable to floods and changing land use requires new methods and rapid approaches to achieve concrete and relevant results in urban areas.

\section{CONCLUSIONS}

The applied methodology allowed identifying areas with a high and very high risk of floods in the city of Codlea. The proposed methods can be used both for large or small river basins and for localities, where anthropogenic activity has a significant impact on the environment, impacting that can generate significant floods or floods.

The proposed model is a tool that assesses flood risk, especially for areas where we do not have maps or relevant information to discover susceptibility to such natural disasters.

By analyzing characteristic factors that directly impact the generation of floods, we can assess the risk caused by them and build a vital tool for implementing public policies that contribute to mitigating these types of natural hazards and preventing human or economic losses.

This model has very high applicability and is easy to achieve, being even necessary for many areas where land use is continuously changing, and new factors appear to increase the risk of a flood. The advantage of the presented model is that it can be achieved at a low cost by an average trained staff, using open-source data and maximum benefits.

\section{REFERENCES}

Althuwaynee, O. F., Pradhan, B., Park, H. J., and Lee, J. H. (2014). “A novel ensemble bivariate statistical evidential belief function with knowledge-based analytical 
hierarchy process and multivariate statistical logistic regression for landslide susceptibility mapping." Catena, 114.

Barredo, J. I. (2007). "Major flood disasters in Europe: 1950-2005." Natural Hazards.

Barredo, J. I., de Roo, A., and Lavalle, C. (2007). "Flood risk mapping at European scale." Water Science and Technology.

Bonham-Carter, G. (2014). "Geographic information systems for geoscientists: modelling with GIS." Computer methods in the geosciences.

Clar, C., Prutsch, A., and Steurer, R. (2013). "Barriers and guidelines for public policies on climate change adaptation: A missed opportunity of scientific knowledge-brokerage." Natural Resources Forum.

Costache, R. (2019a). "Flood Susceptibility Assessment by Using Bivariate Statistics and Machine Learning Models - A Useful Tool for Flood Risk Management." Water Resources Management.

Costache, R. (2019b). "Flash-Flood Potential assessment in the upper and middle sector of Prahova river catchment (Romania). A comparative approach between four hybrid models." Science of the Total Environment, Elsevier B.V., 659, 1115-1134.

Costache, R., Hong, H., and Wang, Y. (2019). "Identification of torrential valleys using GIS and a novel hybrid integration of artificial intelligence, machine learning and bivariate statistics." Catena, Elsevier, 183(April), 104179.

Costache, R., Ngo, P. T. T., and Bui, D. T. (2020). "Novel ensembles of deep learning neural network and statistical learning for flash-flood susceptibility mapping." Water (Switzerland), 12(6).

Diaconu, D. C., Bretcan, P., Peptenatu, D., Tanislav, D., and Mailat, E. (2019). "The importance of the number of points, transect location and interpolation techniques in the analysis of bathymetric measurements." Journal of Hydrology.

Drăghici, C. C., Andronache, I., Ahammer, H., Peptenatu, D., Pintilii, R. D., Ciobotaru, A. M., Simion, A. G., Dobrea, R. C., Diaconu, D. C., Vișan, M. C., and Papuc, R. M. (2017). "Spatial evolution of forest areas in the northern Carpathian mountains of Romania." Acta Montanistica Slovaca.

Feyen, L., Dankers, R., Bódis, K., Salamon, P., and Barredo, J. I. (2012). "Fluvial flood risk in Europe in present and future climates." Climatic Change.

Gashaw, W., and Legesse, D. (2011). "Flood Hazard and Risk Assessment Using GIS and Remote Sensing in Fogera Woreda, Northwest Ethiopia." Nile River Basin.

Greg, S., Smith, G., and Greg, S. (2003). "Flash flood potential: Determining the hydrologic response of ffmp basins to heavy rain by analyzing their physiographic characteristic." ... to the NWS Colorado Basin River Forecast Center.

Hofmann, J., and Schüttrumpf, H. (2019). "Risk-based early warning system for pluvial flash floods: Approaches and foundations.” Geosciences (Switzerland). 
Kruzdlo, R., and Joseph Ceru, noaagov. (n.d.). Flash Flood Potential Index for WFO Mount Holly/Philadelphia Introduction Methodology.

Nohani, E., Moharrami, M., Sharafi, S., Khosravi, K., Pradhan, B., Pham, B. T., Lee, S., and Melesse, A. M. (2019). "Landslide susceptibility mapping using different GIS-Based bivariate models." Water (Switzerland).

Paprotny, D., Morales-Nápoles, O., and Jonkman, S. N. (2017). "Efficient panEuropean river flood hazard modelling through a combination of statistical and physical models." Natural Hazards and Earth System Sciences.

Pintilii, R. D., Andronache, I., Diaconu, D. C., Dobrea, R. C., Zeleňáková, M., Fensholt, R., Peptenatu, D., Drăghici, C. C., and Ciobotaru, A. M. (2017). "Using fractal analysis in modeling the dynamics of forest areas and economic impact assessment: Maramures, County, Romania, as a case study." Forests.

Popa, M. C., Peptenatu, D., Draghici, C. C., and Diaconu, D. C. (2019). "Flood hazard mapping using the flood and Flash-Flood Potential Index in the Buzau River catchment, Romania." Water (Switzerland), 11(10).

Popa, M. C., Simion, A. G., Peptenatu, D., Dima, C., Draghici, C. C., Florescu, M. S., Dobrea, C. R., and Diaconu, D. C. (2020). "Spatial assessment of flash-flood vulnerability in the Moldova river catchment (N Romania) using the FFPI." Journal of Flood Risk Management, 13(4), 1-10.

Samanta, R. K., Bhunia, G. S., Shit, P. K., and Pourghasemi, H. R. (2018). "Flood susceptibility mapping using geospatial frequency ratio technique: a case study of Subarnarekha River Basin, India." Modeling Earth Systems and Environment, $4(1)$.

Sima, A., and Șerban, G. (2015). "The Historical Flood of July 2008 From Vaser River Basin, Romania. Causes, Effects and Flood Control Actions." Present Environment and Sustainable Development.

Tîrnovan, A., Cojoc, G. M., Romanescu, G., and Obreja, F. (1975). Predicting the potential index of major floods production in the Suha river basin (Suha Bucovineana).

Veijalainen, N. (2012). Estimation of climate change impacts on hydrology and floods in Finland. Aalto University.

Wu, W., and Sidle, R. C. (1995). "A Distributed Slope Stability Model for Steep Forested Basins." Water Resources Research.

Zaharia, L., Costache, R., Prăvălie, R., and Ioana-Toroimac, G. (2017). "Mapping flood and flooding potential indices: a methodological approach to identifying areas susceptible to flood and flooding risk. Case study: the Prahova catchment (Romania)." Frontiers of Earth Science, 11(2), 229-247.

Zaharia, L., Minea, G., Ioana-Toroimac, G., Barbu, R., and Sârbu, I. (2012). "Estimation of the Areas with Accelerated Surface Runoff in the Upper Prahova Watershed (Romanian Carpathians)." BALWOIS 2012 -Ohrid. 
Zeleňáková, M., Gaňová, L., Purcz, P., and Satrapa, L. (2015). "Methodology of flood risk assessment from flash floods based on hazard and vulnerability of the river basin." Natural Hazards.

Zeng, Z., Tang, G., Long, D., Zeng, C., Ma, M., Hong, Y., Xu, H., and Xu, J. (2016). "A cascading flash flood guidance system: development and application in Yunnan Province, China.” Natural Hazards, Springer Netherlands, 84(3), 20712093. 